\title{
Study of soil contamination near R1-Barzina artesian borehole, Vratsa Province
}

\section{Изследване на замърсяването на почви в близост до сондаж на самоизлив R1-Бързина, област Враца}

\author{
Mila Trayanova ${ }^{1}$, Sava Kolev ${ }^{1}$, Diana Rabadjieva ${ }^{2}$, Aleksey Benderev ${ }^{1}$, Rumiana Gergulova ${ }^{2}$ \\ Мила Траянова ${ }^{1}$, Сава Колев ${ }^{1}$, Диана Рабаджиева ${ }^{2}$, Алексей Бендерев ${ }^{1}$, Румяна Гергулова ${ }^{2}$ \\ ${ }^{1}$ Geological Institute, Bulgarian Academy of Sciences, Acad. G. Bonchev str., bl. 24, 1113 Sofia; \\ E-mails: milatr@abv.bg, sava_kolev@geology.bas.bg, alekseybenderev@yahoo.com \\ ${ }^{2}$ Institute of General and Inorganic Chemistry, Bulgarian Academy of Sciences, Acad. G. Bonchev str., bl. 11, 1113 Sofia; \\ E-mails: didiarab@svr.igic.bas.bg, rumigg@yahoo.com
}

\begin{abstract}
The purpose of the present study is to evaluate the environmental impact of a surface spill of groundwater with high total dissolved solids content by clarifying the extent of contamination in the soil layer near the borehole R1 - Barzina. The overall tendency for limitation of the migration of chloride pollution in the immediate vicinity of the formed surface spill. The fluctuations of the chlorides content in depth indicates the seasonal impact of refreshment by atmospheric waters.
\end{abstract}

Keywords: exploration borehole, ecological assessment, soils, chlorides, Barzina.

\section{Въведение}

При търсенето и проучването на нефт и газ на територията на Северна България през втората половина на XX век са прокарани над 1500 сондажа, чиято дълбочина варира от няколкостотин до над 5000 m (Stoyanov et al., 2015). При прокарването на сондажните изработки с различно предназначение (за търсене и разкриване на геоложки структури, оконтурване на вече открити залежи от въглеводороди, мониторинг и експлоатация на установените находища и др.) често са разкривани подземни води с напор над земната повърхност. Впоследствие, тъй като много от сондажите не са ликвидирани, на земната повърхност са възникнали разливи, които крият опасност от замърсяване на почвите в близост до тях, както и на повърхностните и плиткозалягащите подземни води (Trayanova, Benderev, 2018a, b; Kolev, Hristov, 2019; Kolev et al., 2019). Подобен е случаят със сондаж R1-Бързина, където се наблюдава дългогодишен самоизлив на води с повишена минерализация. Целта на настоящото изследване е да бъде оценено екологичното въздействие на образувалия се на повърхността разлив, като бъде изяснен обхвата на замър- сяването с хлориди в почвения слой в близост до сондажа.

\section{Обект на изследване}

Сондаж R1-Бързина е разположен в Северозападна България, на около $1 \mathrm{~km}$ ЮИ от центъра на с. Бързина (община Хайредин, област Враца) на кота $121 \mathrm{~m}$ н. в. По време на сондажните работи са преминати два напорни водоносни хоризонта: горнокреден (варовици) и средноюрски (пясъчници), като крайната му дълбочина е достигнала $4361 \mathrm{~m}$. Водите на по-горния водоносен хоризонт са изолирани чрез циментация и на повърхността се дренират води само от средноюрския водоносен хоризонт (разкрит в интервала 3733-828 m). Те са с висока обща минерализация (около $30 \mathrm{~g} / 1$ ) и общо съдържание на хлориди $19700 \mathrm{mg} / \mathrm{l}$. Около сондажа е образуван разлив с площ $150 \mathrm{~m}^{2}$, който се дренира от поток, течащ в североизточно направление, в продължение на 50 m, преди да се загуби под земната повърхност. Понастоящем устието на сондажа е под водното ниво на разлива, като се наблюдава голямо количество газ, излизащо от него, а според жители на с. Бързина се наблюдава и пе- 
риодично фонтаниране на газ и вода от сондажа на височина няколко метра.

\section{Методика и получени резултати}

За охарактеризиране на изтичащите подземни води на място са определени някои физикохимични показатели на водите - $\mathrm{pH}$, специфична електропроводимост, съдържание на разтворен кислород и температура, и са взети водни проби от 3 пункта - устието на сондажа, изтичането от разлива и от края на потока преди губенето му под земната повърхност. За всеки пункт са взети по 2 водни проби в стерилни PVC бутилки, предназначени за лабораторно изследване на катионите и анионите, и са транспортирани в хладилна чанта до лаборатория, като пробата за катиони е консервирана с киселина $(\mathrm{HCl})$. Взетите водни проби са изследвани в лаборатория за изпитване и калибриране „ЛИПГЕИ“ - София.

С цел да се оцени актуалното състояние на екологичното влияние на високоминерализираните подземни води, изливащи се на земната повърхност, са взети почвени проби по 5 профила, разположени на различна дистанция - под повърхността на разлива, образуван около сондажа и надолу по течението на дрениращия го поток. Дълбочината на опробване е $1 \mathrm{~m}$, като са взети проби от 5 различни дълбочинни интервала $(0-20,20-40,40-60,60-80$ и 80-100 cm). Определянето на съдържанията на хлориди в почвените проби е извършено в Института по обща и неорганична химия при БАН, като е приложена стандартна методика за екстракция на водоразтворими елементи от почви. 3 g въздушно суха почва, пресята през сито с размер $1 \mathrm{~mm}$, са смесени с $30 \mathrm{ml}$ дестилирана вода (съотношение почва:вода=1:10) при интензивно разбъркване в продължение на $30 \mathrm{~min}$. Суспензията е центрофугирана в продължение на $60 \mathrm{~min}$ при ротационна скорост $4000 \mathrm{rpm}$ и филтрувана през мембранен филтьр 0,45 $\mu \mathrm{m}$. Хлоридните йони са определени спектрофотометрично със спектрофотометьр NOVA 60, Merck и Spectroquant® тестове. Получените резултати от лабораторните изпитвания са представени като изменение на съдържанията на хлориди в дълбочина в почвения профил (фиг. 1).

Резултатите от лабораторния анализ (табл. 1) показват, че водите, изтичащи от сондажа, са от хлоридно-натриев тип с висока минерализация $(30,3 \mathrm{~g} / 1)$ и с общо съдържание на хлориди 19,7 g/1 и на $\mathrm{Na} 8,3 \mathrm{~g} / \mathrm{l}$. Високи стойности се наблюдават и за концентрациите на сулфати, $\mathrm{Ca}, \mathrm{Fe}, \mathrm{Mn}$ и B, които неколкократно надвишават стандарта за качество на подземните води според Наредба №1/10.10.2007 г. за проучване, ползване и опазване на подземните води. Все пак, в повърхностния разлив и надолу по течението на дрениращия го поток се наблюдава обща тенденция към намаляване на концентрациите на посочените химични компоненти, като най-показателен е примерът с желязото - редуциране от $19,9 \mathrm{mg} / 1$ до 0,019 mg/l. Това вероятно се дължи на факта, че след изтичане на повърхността температурата на водите значително намалява, контактът с кислород от атмосферния въздух води до промяна на окислително-редукционния потенциал, а преминаването на $\mathrm{CO}_{2}$ от тях към атмосферата
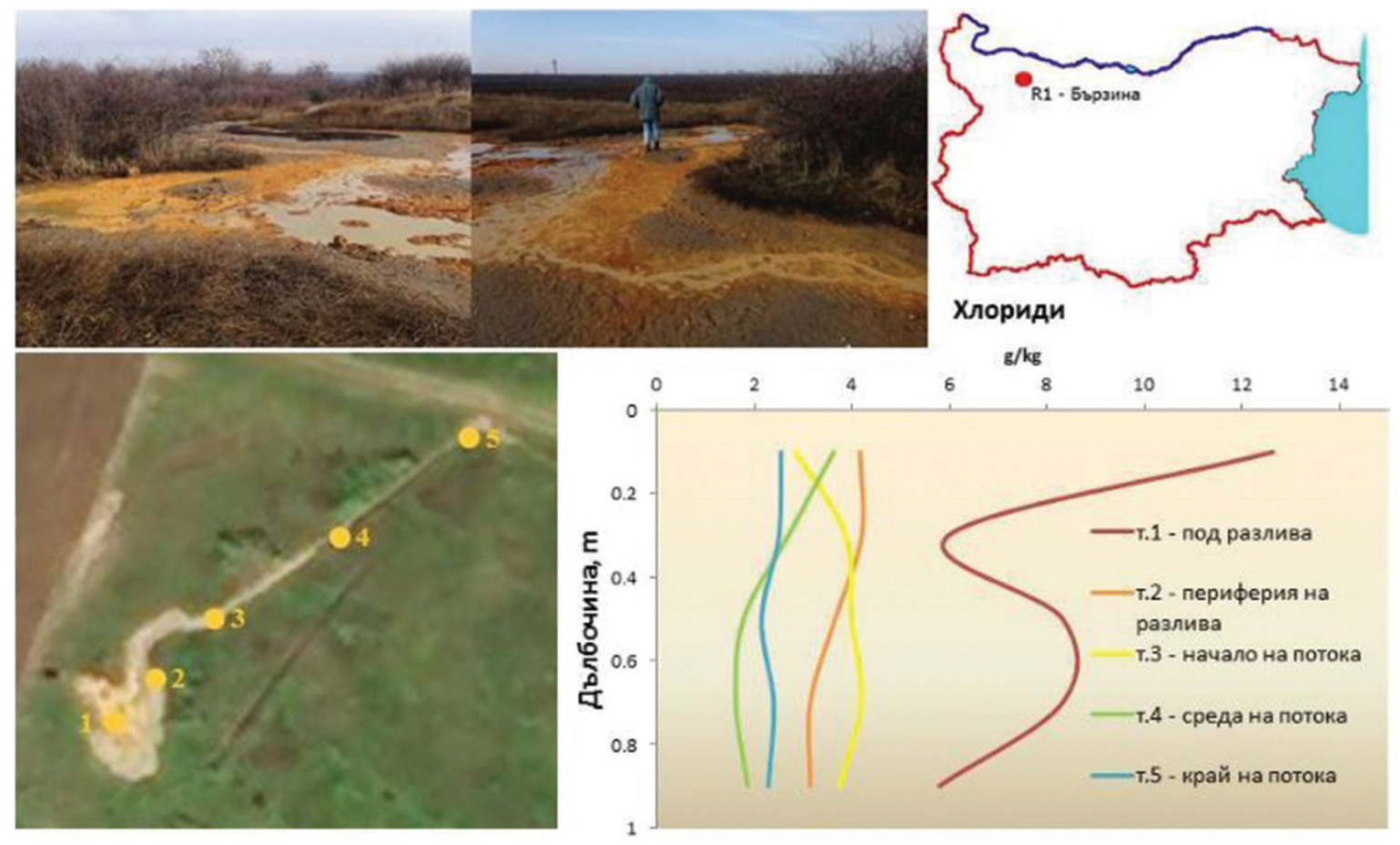

Фиг. 1. Местоположение и изглед на разлива около сондаж R1-Бързина и съдържание на хлориди в почвения профил 
Таблица 1. Резултати от лабораторен анализ на водни проби, съпоставени със стандарта за качество на подземните води според Наредба №1/10.10.2007 г.

\begin{tabular}{|c|c|c|c|c|c|}
\hline Показател & $\begin{array}{l}\text { Единица на } \\
\text { величината }\end{array}$ & Сондаж (устие) & $\begin{array}{c}\text { Разлив около } \\
\text { сондажа }\end{array}$ & Край на потока & Стандарт \\
\hline Амониев йон & $\mathrm{mg} / \mathrm{l}$ & 0,30 & 0,18 & 0,09 & 0,5 \\
\hline Нитрати & $\mathrm{mg} / 1$ & 3,4 & 3,4 & 2,3 & 50 \\
\hline Нитрити & $\mathrm{mg} / \mathrm{l}$ & 0,14 & 0,05 & 0,06 & 0,5 \\
\hline Фосфати & $\mathrm{mg} / 1$ & 0,06 & 0,04 & 0,08 & 0,5 \\
\hline Хлориди & $\mathrm{mg} / 1$ & 19700 & 14200 & 15400 & 250 \\
\hline Сулфати & $\mathrm{mg} / 1$ & 400 & 395 & 385 & 250 \\
\hline Хидрогенкарбонати & $\mathrm{mmol} / \mathrm{l}$ & 19,5 & 13,7 & 12,2 & \\
\hline I & $\mathrm{mg} / 1$ & 0,36 & 5,3 & 9,6 & \\
\hline $\mathrm{Br}$ & $\mathrm{mg} / \mathrm{l}$ & 2,12 & 0,110 & 0,25 & \\
\hline $\mathrm{Ca}$ & $\mathrm{mg} / \mathrm{l}$ & 313 & 293 & 230 & 150 \\
\hline $\mathrm{Mg}$ & $\mathrm{mg} / 1$ & 28 & 27 & 25 & 80 \\
\hline $\mathrm{Na}$ & $\mathrm{mg} / 1$ & 8371 & 8142 & 7570 & 200 \\
\hline K & $\mathrm{mg} / \mathrm{l}$ & 3,4 & 4,6 & 5,7 & \\
\hline $\mathrm{Fe}$ & $\mathrm{mg} / \mathrm{l}$ & 19,9 & 0,014 & 0,019 & 0,2 \\
\hline $\mathrm{Cu}$ & $\mathrm{mg} / \mathrm{l}$ & 0,0165 & 0,0058 & 0,0071 & 0,2 \\
\hline $\mathrm{Mn}$ & $\mathrm{mg} / \mathrm{l}$ & 1,71 & 1,68 & 1,27 & 0,05 \\
\hline B & $\mathrm{mg} / 1$ & 220 & 213 & 203 & 1 \\
\hline $\mathrm{Si}$ & $\mathrm{mg} / 1$ & 20,0 & 14,1 & 10,5 & \\
\hline $\mathrm{Li}$ & $\mathrm{mg} / 1$ & 5,3 & 5,2 & 5,0 & \\
\hline $\mathrm{Sr}$ & $\mathrm{mg} / 1$ & 31,1 & 28,2 & 25,9 & \\
\hline As & $\mathrm{mg} / 1$ & $<0,005$ & 0,0065 & 0,0056 & 0,01 \\
\hline $\begin{array}{l}\text { Перманганатна } \\
\text { окисляемост }\end{array}$ & $\mathrm{mgO}_{2} / 1$ & 61 & 46 & 50 & 5 \\
\hline
\end{tabular}

или обратно - до промени в $\mathrm{pH}$. Това съществено влияе на валентността, в която се намира желязото във водата, съответно на неговите миграционни форми и възможности на разтваряне и отлагане на различни минерални фази. Тук явно се наблюдава изключително бързо отлагане в близост до сондажа и се предотвратява по-далечната миграция чрез повърхностния воден поток.

По отношение на миграцията на хлоридите в дълбочина в почвения профил под разлива и под дрениращия го поток, най-общо се наблюдава тенденция към намаляване на концентрациите в дълбочина, както и към периферията на разлива и с отдалечаване от сондаж R1 надолу по потока. Правят впечатление флуктуациите, наблюдавани под самия разлив в непосредствена близост до сондажа, които вероятно се дължат на периодичното влияние на атмосферни води от обилни валежи и снеготопене, при което се получава опресняване на инфилтриращите се в почвата води и навлизане в дълбочина на фронт с по-ниски концентрации на хлориди.

\section{Заключение}

Проведените изследвания показват общата тенденция за ограничаване на миграцията на замърсяването с хлориди в непосредствена близост до образувалия се повърхностен разлив. За по-пълно изясняване на влиянието на периодичното опресняване на инфилтриращите се високоминерализирани води и процесите, протичащи при миграцията на хлоридите в почвата, е необходимо провеж- дането на допълнителни изследвания с по-голяма дълбочина на проучвателния профил.

Благодарности: Изследването е реализирано с подкрепата на Министерството на Образованието и Науката в рамките на Национална програма „Млади учени и постдокторанти“.

\section{Литература \\ References}

Kolev, S., N. Hristov. 2019. Preliminary environmental impact assessment of R10 - Septemvriytsi borehole, Montana Province. - Rev. Bulg. Geol. Soc., 80, 3, 168-169 (in Bulgarian with English abstract).

Kolev, S., M. Trayanova, H. Stanev, N. Hristov. 2019. Ecological status of old oil boreholes in Central Northern Bulgaria. - Proc. 19th Intern. Multidisciplinary Sci. GeoConfer. SGEM 2019, 19, 1.2, 161-167; https://doi.org/10.5593/ sgem2019/1.2/S02.021.

Stoyanov, N., P. Gerginov, A. Benderev, K. Boyadjieva, V. Hristov, V. Vesselinov. 2015. Assessment and prediction of potential contamination of groundwater in exploration and production of oil and gas. - Rev. Bulg. Geol. Soc., 76, 2-3, 79-88 (in Bulgarian with English abstract).

Trayanova, M., A. Benderev. 2018a. Actual state and problems of artesian old oil boreholes in Northern Bulgaria. - Rev. Bulg. Geol. Soc., 79, 3, 155-156 (in Bulgarian with English abstract).

Trayanova, M., A. Benderev. 2018b. Ecological assessment of artesian water from well near village of Rasovo (NW Bulgaria). - Proc. 18th Intern. Multidisciplinary Sci. GeoConfer. SGEM 2018, 18, 1.2, 223-230; https://doi.org/ $10.5593 / \mathrm{sgem} 2018 / 1.2 / \mathrm{S} 02.028$. 